\title{
Study on Inhibition of N80 Carbon Steel in 0.5M KCl Solution Saturated with $\mathrm{CO}_{2}$ by Gum Arabic
}

\author{
Gaetano Palumbo $^{\mathrm{a} *}$, Jacek Banaśa \\ ${ }^{a}$ AGH University of Science and Technology, Faculty of Foundry Engineering, Reymonta 23, 30-059 Krakow, Poland \\ *e-mail: gpalumbo@agh.edu.pl
}

Received: 15 Sptember 2017/Accepted: 8 March 2018/Published online: 30 March 2018

This article is published with open access at AGH University of Science and Technology

\begin{abstract}
The effect of Gum Arabic (GA) on the corrosion of an N80 carbon steel pipeline in a $\mathrm{CO}_{2}$-saturated chloride $(0.5 \mathrm{M} \mathrm{KCl})$ solution was investigated through AC impedance and polarization curves. Potentiodynamic measurements showed that the corrosion current density decreased in the presence of inhibitors and that the inhibitor acts like a mixed-type inhibitor, with anodic predominance. The Nyquist diagrams showed an increase in polarization resistance values in the presence of the inhibitor, thus increasing inhibition efficiency. At higher temperatures, the inhibition efficiency decreased, implying that the inhibition action of GA occurred via the physical adsorption process. The activation parameters of the corrosion process such as activation energies, $E_{a}$, and the heat of adsorption, $Q_{a d s^{\prime}}$, were calculated, respectively, by the obtained corrosion rate and inhibition efficiency at different temperatures. At higher temperatures, the increase in activation energy combined with the negative levels of the heat of adsorption further supported the physical adsorption nature of the process.
\end{abstract}

\section{Keywords:}

corrosion inhibition, gum arabic, carbon steel, electrochemical techniques

\section{INTRODUCTION}

Despite its relatively limited corrosion resistance, carbon steelis widely used in oiland gasindustry infrastructures mainly due to its low cost. One of the most-practical methods to protect the metal dissolution from aggressive environments is the use of inhibitors. In particular, organic inhibitors provide more environmental benefits than the traditional toxic ones, meeting the stringent environment regulations that limit their consumption. Commercial gum arabic was selected for the present study. GA is a water-soluble and complex mixture of arabinogalactan, oligosaccharides, polysaccharides, and glucoproteins [1] and is biodegradable and readily available from renewable sources [2]. As witnessed by an increasing number of publications, GA is emerging as a promising candidate as a corrosion inhibitor of metal infrastructures [2-7]. It was reported that the inhibition process by GA is mainly attributed to the adsorption of the chain molecules via their functional group onto the metal surface (i.e., hydroxyl functional group $(-\mathrm{OH})$, and carboxyl functional group $(-\mathrm{COOH})$ ) [2-8]. One of the most-frequent and aggressive environments found in the oil and gas industry are fluids with high concentrations of chlorides containing carbon dioxide $[9,10]$. It is well-known that the presence of chloride ions leads to an autocatalytic process dissolution of the metal owing to the breakdown of the oxide layers on the metal surface by localized corrosion spots [11-13]. Moreover, the literature reports that the corrosion rate in chloride water is enhanced by a factor of around 16 by the presence of $\mathrm{CO}_{2}$ [14]. Therefore, the objective of the research presented in this paper was to study the inhibition effect of GA on $\mathrm{N} 80$ carbon steel pipeline in $\mathrm{CO}_{2}$-saturated chloride solutions for the first time.

The study was carried out using electrochemical techniques such as electrochemical impedance spectroscopy (EIS) and linear sweep voltammetry (LSV).

\section{EXPERIMENTAL}

The electrochemical experiments were performed by using three electrode cells connected to a Potentiostat/ Galvanostat Gamry reference 600. N80 carbon steel was used as a working electrode, a platinum electrode as an auxiliary electrode, and a saturated calomel electrode (SCE) as a reference electrode. All potentials reported were measured versus SCE. The electrical connection of the specimen to the potentiostat was achieved by spot welding an insulated copper wire onto an unexposed electrode surface. All of the experiments were conducted at 25 and $45^{\circ} \mathrm{C}$ in an unstirred solution consisting of a $\mathrm{CO}_{2}$-saturated chloride $(0.5 \mathrm{M} \mathrm{KCl})$ solution with and without the presence of the inhibitor gum arabic (GA) (e.g., $0.5 \mathrm{~g} / \mathrm{l}$ ). The solutions were prepared from analytical-grade material (SIGMA-ALDRICH) and distilled water with $0.055 \mu \mathrm{S} \cdot \mathrm{cm}^{-1}$ of conductivity. The efficiency of the inhibitor was evaluated via linear sweep voltammetry (LSV) and electrochemical impedance spectroscopy (EIS). Tafel curves were obtained at a scan rate of $1.0 \mathrm{mV} \cdot \mathrm{s}^{-1}$. EIS measurements were performed under potentiostatic 
conditions in a frequency range of $100 \mathrm{kHz}$ to $0.01 \mathrm{~Hz}$, with an AC signal with an amplitude of $10 \mathrm{mV}$. In both electrochemical techniques, the measure started after exposing the sample for $24 \mathrm{~h}$ in the tested solution. The data was then collected and fitted with a Gamry echem analyst in order to calculate inhibitor efficiency $(E I \%)$ and the corrosion rate (CR).

\section{RESULTS AND DISCUSSION}

\subsection{EIS measurements}

Nyquist plots of $\mathrm{N} 80$ pipe carbon steel in a $0.5 \mathrm{M} \mathrm{KCl}$ solution saturated with $\mathrm{CO}_{2}$ with the absence and presence of $0.5 \mathrm{~g} / \mathrm{l}$ of GA performed at 25 and $45^{\circ} \mathrm{C}$ are shown in Figures $1 \mathrm{a}$ and $\mathrm{b}$. The EIS results of these capacitive loops are simulated by an equivalent circuit containing a parallel combination of constant phase element $(Q)$ with polarization resistance $\left(R_{p}\right)$ and solution resistant $\left(R_{s}\right)$ (e.g., $\left.R_{s}\left(Q R_{p}\right)\right)$. It can be seen that, after the addition of GA, the impedance modulus of the system increased at both temperatures. The increase of polarization resistance $\left(R_{p}\right)$ with respect to a blank $0.5 \mathrm{M}$ $\mathrm{KCl}$ solution as shown in Table 1 is attributed to the increase in resistance and adsorption of inhibitor molecules on the steel surface $[2,4,6]$.

a)

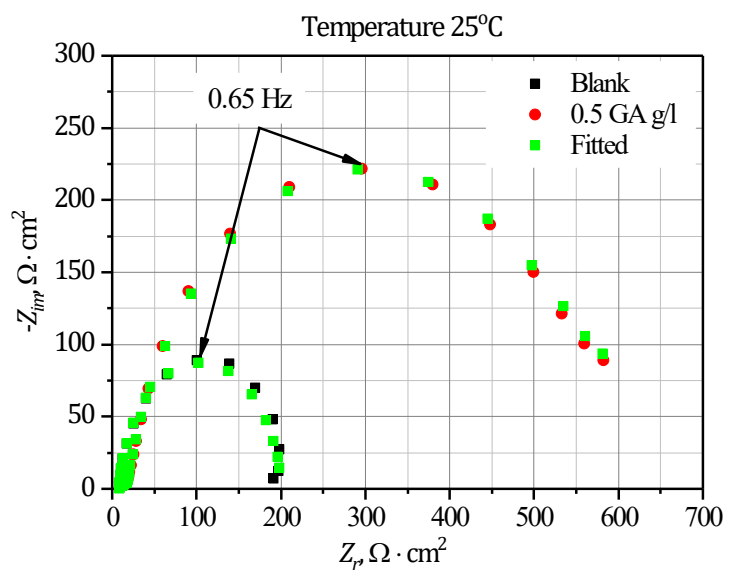

b)

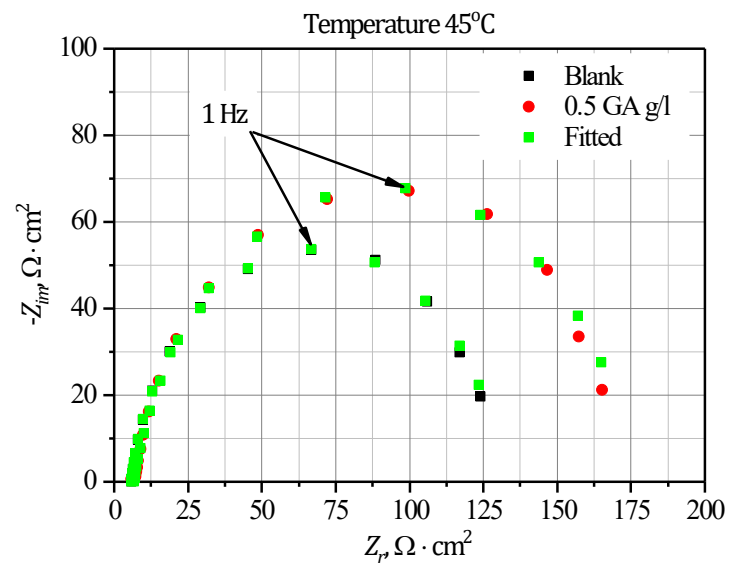

Fig. 1. Nyquist plots recorded at OCP after 24 hours of exposure for carbon steel $(\mathrm{N}-80)$ pipeline steel in $\mathrm{CO}_{2}$-saturated chloride $(0.5 \mathrm{M} \mathrm{KCl})$ solution in absence and presence of GA $(0.5 \mathrm{~g} / \mathrm{l})$ within temperature range of $25^{\circ} \mathrm{C}(\mathrm{a})$ and $45^{\circ} \mathrm{C}(\mathrm{b})$
Table 1

Electrochemical parameters obtained from EIS within temperature range of $25-45^{\circ} \mathrm{C}$ after 24 hours of exposure

\begin{tabular}{|c|c|c|c|c|}
\hline \multicolumn{5}{|c|}{ Temperature $25^{\circ} \mathrm{C}$} \\
\hline $\begin{array}{c}C_{i n h^{\prime}} \\
\mathrm{g} \cdot \mathrm{l}^{-1} \\
\end{array}$ & $\begin{array}{c}R_{s^{\prime}} \\
\Omega \cdot \mathbf{c m}^{2}\end{array}$ & $\begin{array}{c}R_{p}, \\
\Omega \cdot \mathbf{c m}^{2} \\
\end{array}$ & $\begin{array}{c}C R, \\
\mathrm{~mm} \cdot \mathrm{yr}^{-1} \\
\end{array}$ & $\begin{array}{l}E I, \\
\% \\
\end{array}$ \\
\hline Blank & 8.79 & 192.00 & 0.00157 & - \\
\hline 0.5 & 9.23 & 561.00 & 0.00054 & 65.78 \\
\hline \multicolumn{5}{|c|}{ Temperature $45^{\circ} \mathrm{C}$} \\
\hline $\begin{array}{c}C_{i n h^{\prime}} \\
\mathrm{g} \cdot \mathrm{l}^{-1}\end{array}$ & $\begin{array}{c}R_{S^{\prime}} \\
\Omega \cdot \mathbf{c m}^{2}\end{array}$ & $\begin{array}{c}R_{p} \\
\Omega \cdot \mathbf{c m}^{2}\end{array}$ & $\begin{array}{c}C R, \\
\mathrm{~mm} \cdot \mathrm{yr}^{-1}\end{array}$ & $\begin{array}{l}E I, \\
\%\end{array}$ \\
\hline Blank & 5.96 & 125.00 & 0.00248 & - \\
\hline 0.5 & 6.77 & 170.00 & 0.00178 & 26.47 \\
\hline
\end{tabular}

The inhibition efficiency was calculated using polarization resistance $\left(R_{p}\right)$ as follows:

$$
E I \%=\frac{R_{p}^{i}-R_{p}}{R_{p}^{i}} \cdot 100
$$

where $R_{p}^{i}$ band $R_{p}$ are the values of the polarization resistance in the presence and absence of the inhibitor in the tested solution, respectively. Whereas, the corrosion rate $(C R)$ is calculated from the following equation according ASTM Standard G 102 [15]:

$$
C R=K \frac{i_{\text {corr }}}{\rho}(E W)
$$

where $K\left(3272 \mathrm{~mm} \mathrm{~A}^{-1} \cdot \mathrm{cm}^{-1} \cdot \mathrm{yr}^{-1}\right)$ is a constant for converting units, $i_{\text {corr }}$ is the current density $\left(\mathrm{A} \cdot \mathrm{cm}^{-2}\right), \rho$ is the density of the corroded metal (steel: $7.85 \mathrm{~g} \cdot \mathrm{cm}^{-3}$ ), and $E W$ (Fe: $27.93 \mathrm{~g} \cdot$ eq $^{-1}$ ) is the element equivalent weight.

The corrosion parameters obtained by EIS measurements at different temperatures are tabulated in Table 1. It can be clearly seen that the corrosion rate values decreased in the presence of GA. This decrease in $C R$ is ascribed to the formation of a product layer promoted by the adsorption of the inhibitor onto the electrode surface. However, increases in temperature led to increasing the corrosion rate and decreasing the corrosion resistance of the steel in the tested solution. The $E I \%$ is also affected by increases in temperature; as a result, the $E I \%$ decreased from a value of $65.78 \%$ to $26.47 \%$. In fact, the increase in temperature lead to the stimulation of the metal surface kinetic energy [16], which has an adverse effect on the adsorption process; i.e., the adsorption of the inhibitors is significantly reduced, a trend often attributed to the physical adsorption process [6]. The physisorption is consistent with the electrostatic interaction between charged molecules and a charged metal, while the chemisorption is consistent with charge sharing or transfer from the inhibitor components to the metal surface to form a co-ordinate type of bond [17]. The inhibition effect of Gum Arabic is attributed to the presence of hydroxyl functional group $(-\mathrm{OH})$ and carboxyl functional group $(-\mathrm{COOH})$ [2]. In an acid solution, the carbonyl oxygen $(\mathrm{C}=0)$ may be protonated, and the molecule exists as a polycation [18]. While in the presence of $\mathrm{Cl}^{-}$anions, the metal surface can be 
negatively charged by the adsorption of these anions on its surface. The adsorption, therefore, is the result of an electrostatic interaction between the GA molecules and mild steel surface $[19,20]$.

\subsection{LSV measurements}

Figures 2a and b show the polarization curves for N80 pipe carbon steel in the absence and presence of the inhibitor in the tested solution, performed respectively at 25 and $45^{\circ} \mathrm{C}$. Table 2 contains all of the electrochemical corrosion kinetic parameters such as corrosion potential $\left(E_{\text {corr }}\right)$, corrosion current density $\left(i_{\text {corr }}\right)$, corrosion rate $(C R)$, and inhibition efficiency $(E I \%)$.

The inhibition efficiency was calculated using the corrosion current density as follows:

$$
E I \%=\frac{i_{\text {corr }}-i_{\text {corr }}^{i}}{i_{\text {corr }}} \cdot 100
$$

where $i_{\text {corr }}$ and $i_{\text {corr }}^{i}$ are the corrosion current densities in the absence and presence of inhibitor.

From Figure 2 and Table 2, it is can be seen that, by adding the inhibitor in the tested solution, the current density of both the cathodic and anodic branches markedly decreases towards lower values when compared to the blank solution at both temperatures due to the adsorption of the inhibitor on the metal surface [6]. However, by adding GA, the corrosion potential does not shift remarkably, suggesting that the inhibitor acts as a mixed-type inhibitor.

a)

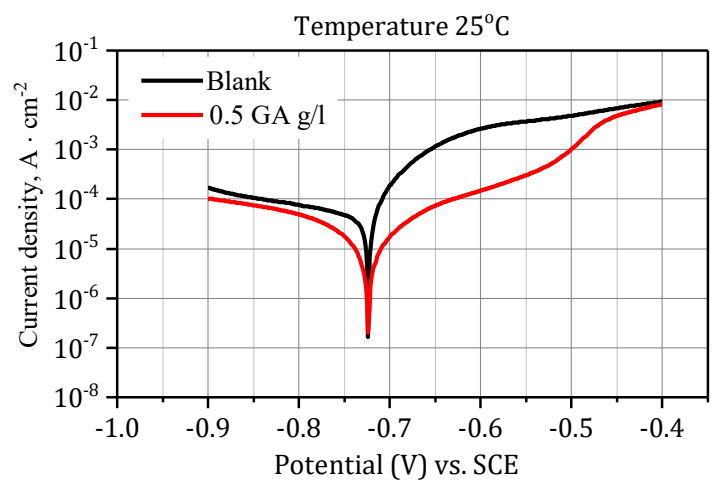

b)

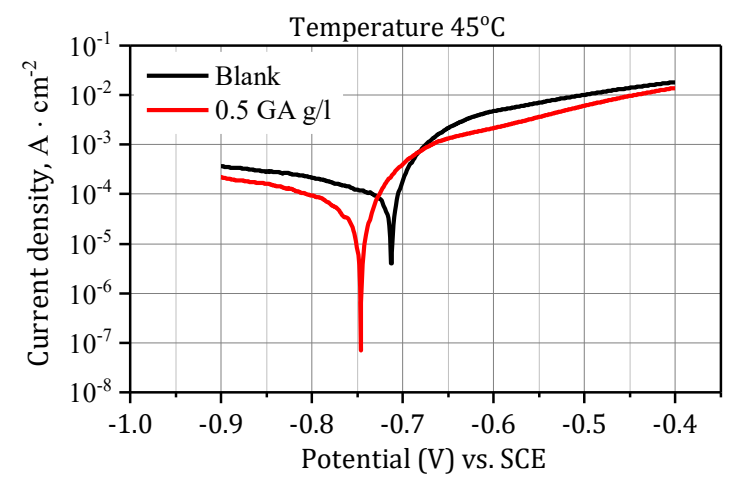

Fig. 2. Polarization curves recorded at OCP after 24 hours of exposure for carbon steel ( $\mathrm{N}-80)$ pipeline steel in $\mathrm{CO}_{2}$-saturated chloride $(0.5 \mathrm{M} \mathrm{KCl})$ solution in absence and presence of $\mathrm{GA}(0.5 \mathrm{~g} / \mathrm{l})$ within temperature range of $25^{\circ} \mathrm{C}$ (a) and $45^{\circ} \mathrm{C}$ (b)
The findings were in well-agreement with those obtained from the EIS measurements, with the values of the $E I \%$ decreasing from 70.26 to 47.48 at the higher temperature.

Table 2

Potentiodynamic polarization parameters for carbon steel $(\mathrm{N}-80)$ pipeline steel in $\mathrm{CO}_{2}$-saturated chloride $(0.5 \mathrm{M} \mathrm{KCl})$ solution at different concentrations of GA after 24 hours of exposure

\begin{tabular}{|c|c|c|c|c|}
\hline \multicolumn{5}{|c|}{ Temperature $25^{\circ} \mathrm{C}$} \\
\hline $\begin{array}{c}C_{i n h^{\prime}} \\
\mathrm{g} \cdot \mathrm{l}^{-1}\end{array}$ & $\begin{array}{c}E_{c o r r} \\
\text { V/SCE }\end{array}$ & $\begin{array}{c}i_{\text {corr }} \\
\mu \mathrm{A} \cdot \mathbf{c m}^{-2}\end{array}$ & $\begin{array}{c}C R, \\
\mathrm{~mm} \cdot \mathrm{yr}^{-1}\end{array}$ & $\begin{array}{l}E I, \\
\%\end{array}$ \\
\hline Blank & -0.726 & 117.6 & 0.00137 & - \\
\hline 0.5 & -0.724 & 34.97 & 0.00041 & 70.26 \\
\hline \multicolumn{5}{|c|}{ Temperature $45^{\circ} \mathrm{C}$} \\
\hline $\begin{array}{c}C_{i n h^{\prime}} \\
\mathrm{g} \cdot \mathrm{l}^{-1}\end{array}$ & $\begin{array}{c}E_{c o r r^{\prime}} \\
\text { V/SCE }\end{array}$ & $\begin{array}{c}i_{\text {corr }} \\
\mu \mathrm{A} \cdot \mathbf{c m}^{-2}\end{array}$ & $\begin{array}{c}C R, \\
\mathrm{~mm} \cdot \mathrm{yr}^{-1}\end{array}$ & $\begin{array}{l}E I, \\
\%\end{array}$ \\
\hline Blank & -0.713 & 156.60 & 0.00182 & - \\
\hline 0.5 & -0.746 & 82.25 & 0.00096 & 47.48 \\
\hline
\end{tabular}

\subsection{Effect of temperature}

To understand the effect of the inhibitor on corrosion rates at different temperatures, the linearized Arrhenius equation of chemical kinetics was considered:

$$
\log C R=\log A-\frac{E_{a}}{2.303 R T}
$$

Here, $A$ is the frequency factor and $E_{a}$ is the apparent activation energy, $R$ is the gas constant $\left(8.314 \mathrm{~J} \cdot \mathrm{mol}^{-1} \cdot \mathrm{K}^{-1}\right)$, and $T$ is the absolute temperature $(\mathrm{K})$.

The Arrhenius equation can be rearranged in the following equation:

$$
\log \frac{C R_{2}}{C R_{1}}=\frac{E_{a}}{2.303 R}\left(\frac{1}{T_{1}}-\frac{1}{T_{2}}\right)
$$

where $C R_{1}$ and $C R_{2}$ are the values of the corrosion rates at temperatures $T_{1}\left(25^{\circ} \mathrm{C}\right)$ and $T_{2}\left(45^{\circ} \mathrm{C}\right)$, respectively.

The values of $E_{a}$ (Tab. 3) were found to increase from $13.97 \mathrm{~kJ} \cdot \mathrm{mol}^{-1}$ in the blank solution to $49.4875 \mathrm{~kJ} \cdot \mathrm{mol}^{-1}$ and from 11.20 to $33.55 \mathrm{~kJ} \cdot \mathrm{mol}^{-1}$ with the addition of $\mathrm{GA}$ at 25 and $45^{\circ} \mathrm{C}$, respectively.

Table 3

\begin{tabular}{|c|c|c|}
\hline \multicolumn{3}{|c|}{ EIS } \\
\hline $\begin{array}{c}C_{i n h^{\prime}} \\
\mathrm{g} \cdot \mathrm{l}^{-1}\end{array}$ & $\begin{array}{c}E_{d^{\prime}} \\
\mathrm{kJ} \cdot \mathrm{mol}^{-1}\end{array}$ & $\begin{array}{c}Q_{a d s^{\prime}} \\
\mathbf{k J} \cdot \mathrm{mol}^{-1}\end{array}$ \\
\hline Blank & 18.03 & - \\
\hline 0.5 & 47.04 & -66.07 \\
\hline \multicolumn{3}{|c|}{ LVS } \\
\hline $\begin{array}{c}C_{i n h^{\prime}} \\
\mathrm{g} \cdot \mathrm{l}^{-1}\end{array}$ & $\begin{array}{c}E_{d^{\prime}} \\
\mathrm{kJ} \cdot \mathrm{mol}^{-1}\end{array}$ & $\begin{array}{c}Q_{a d s^{\prime}} \\
\mathbf{k J} \cdot \mathrm{mol}^{-1}\end{array}$ \\
\hline Blank & 11.20 & - \\
\hline 0.5 & 33.55 & -48.16 \\
\hline
\end{tabular}

Apparent activation energies and heat of adsorption calculated within temperature range of $25-45^{\circ} \mathrm{C}$ 
Higher values of $E_{a}$ in the presence of inhibitors can be correlated with an increasing thickness in the double layer, which enhances the $E_{a}$ of the corrosion process [18]. Combined with the trend of decreased efficiency in the inhibition, such behavior confirmed the physical adsorption nature of the process $[6,21]$.

Another thermodynamic parameter that further describes the adsorption mechanism operative in the corrosion inhibition process is the heat of adsorption, $Q_{a d s}$ The heat of adsorption is connected to the degree of surface coverage, $\theta(E I \%=100 \cdot \theta)$, through the following relationship [1]:

$$
Q_{a d s}=2,303 R\left[\log \left(\frac{\theta_{2}}{1-\theta_{2}}\right)-\log \left(\frac{\theta_{1}}{1-\theta_{1}}\right)\right] \cdot\left(\frac{T_{1} \cdot T_{2}}{T_{2}-T_{1}}\right)
$$

where $\theta_{1}$ and $\theta_{2}$ are values of the degree of surface coverage at temperatures $T_{1}$ and $T_{2}$, respectively. Negative $Q_{a d s}$ values are consistent with physisorption, while positive values of $Q_{a d s}$ imply chemical adsorption. As can be seen from the calculated values of $Q_{a d s}$ shown in Table 3 , they are all negative (which is consistent with the inhibition physisorption mechanism proposed) [22].

\section{CONCLUSION}

1. GA was found to be an efficient corrosion inhibitor for carbon steel in a $\mathrm{CO}_{2}$-saturated chloride $(0.5 \mathrm{M} \mathrm{KCl})$ solution.

2. GA acts as mixed-type inhibitor by promoting the formation of a product layer, thus lowering both cathodic and anodic current density.

3. At the higher temperature, the inhibition efficiency decreased and activation energy increased, indicating that the inhibition is endothermic in nature, and the adsorption process was more-favored at lower temperatures (physisorption).

4. The negative values of the heat of adsorption further support the physical adsorption nature of the process.

\section{Acknowledgements}

The work was supported by the National Center for Research and Development; project No. PBS1/A2/11/2012.

\section{REFERENCES}

[1] Verbeken D., Dierckx S., Dewettinck K. (2003). Exudate gums: occurrence, production, and applications. Applied Microbiology and Biotechnology, 63(1), 10-21.

[2] Umoren S.A., Obot I.B., Ebenso E.E., Okafor P.C., Ogbobe 0. \& Oguzie E.E. (2006). Gum arabic as a potential corrosion inhibitor for aluminium in alkaline medium and its adsorption characteristics. Anti-Corrosion Methods and Materials, 53(3), 277-282.
[3] Abu-Dalo M.A., Othman A.A. \& Al-Rawashdeh N.A.F. (2012). Exudate Gum from Acacia Trees as Green Corrosion Inhibitor for Mild Steel in Acidic Media. International Journal of Electrochemical Science, 7, 9303-9324.

[4] Bentrah H., Rahaliab Y. \& Chala A. (2014). Gum Arabic as an eco-friendly inhibitor for API 5L X42 pipeline steel in $\mathrm{HCl}$ medium. Corrosion Science, 82, 426-431.

[5] Mobin M. \& Khan M.A. (2013). Investigation on the Adsorption and Corrosion Inhibition Behavior of Gum Acacia and Synergistic Surfactants Additives on Mild Steel in $0.1 \mathrm{M} \mathrm{H}_{2} \mathrm{SO}_{4}$. Journal of Dispersion Science and Technology, 34(11), 1496-1506.

[6] Umoren S.A. (2008). Inhibition of aluminium and mild steel corrosion in acidic medium using Gum Arabic. Cellulose, 15, 751-761.

[7] Umoren S.A., Ogbobe O., Igwe I.O. \& Ebenso E.E. (2008). Inhibition of mild steel corrosion in acidic medium using synthetic and naturally occurring polymers and synergistic halide additives. Corrosion Science, 50(7), 1998-2006.

[8] Tiu B.D.B. \& Advincula R.C. (2015). Polymeric corrosion inhibitors for the oil and gas industry: Design principles and mechanism. Reactive and Functional Polymers, 95, 25-45.

[9] Fink J. (2012). Petroleum engineer's guide to oil field chemicals and fluids. Elsevier.

[10] Fink J. (2013). Hydraulic fracturing chemicals and fluids technology. Gulf Professional Publishing.

[11] Cáceres L., Vargas T. \& Herrera L. (2009). Influence of pitting and iron oxide formation during corrosion of carbon steel in unbuffered NaCl solutions. Corrosion Science, 51(5), 971-978.

[12] Cheng Y.F., Wilmottb M. \& Luoa J.L. (1999). The role of chloride ions in pitting of carbon steel studied by the statistical analysis of electrochemical noise. Applied Surface Science, 152(3-4), 161-168.

[13] Palumbo G., Banaś J., Bałkowiec A., Mizera J. \& Lelek-Borkowska U. (2014). Electrochemical study of the corrosion behaviour of carbon steel in fracturing fluid. Journal of Solid State Electrochemistry, 18(11), 2933-2945.

[14] Linter B.R. \& Burstein G.T. (1999). Reactions of pipeline steels in carbon dioxide solutions. Corrosion Science, 41(1), 117-139.

[15] ASTM G102 - 89 Standard Practice for Calculation of Corrosion Rates and Related Information from Electrochemical Measurements. (2015).

[16] Fares M.M., Maayta A.K. \& Al-Qudah M.M. (2012). Pectin as promising green corrosion inhibitor of aluminum in hydrochloric acid solution. Corrosion Science, 60, 112-117.

[17] Umoren S.A., Obot I.B., Ebenso E.E. \& Obi-Egbedi N.O. (2009). The inhibition of aluminium corrosion in hydrochloric acid solution by exudate gum from Raphia hookeri. Desalination, 247(1-3), 561-572.

[18] Solomon M.M., Umoren S.A., Udosoro I.I. \& Udoh A.P. (2010). Inhibitive and adsorption behaviour of carboxymethyl cellulose on mild steel corrosion in sulphuric acid solution. Corrosion Science, 52(4), 1317-1325.

[19] Umoren S.A. \& Solomon M.M. (2015). Effect of halide ions on the corrosion inhibition efficiency of different organic species - A review. Journal of Industrial and Engineering Chemistry, 21, 81-100.

[20] Umoren S.A., Solomon M.M., Udosoro I.I. \& Udoh A.P. (2010). Synergistic and antagonistic effects between halide ions and carboxymethyl cellulose for the corrosion inhibition of mild steel in sulphuric acid solution. Cellulose, 17(3), 635-648.

[21] Al-Luaibi S.S., Azad S. \& Taobi A.-A.H. (2011). Thermodynamic properties of Amino melamine Formaldehyde as corrosion inhibitor for steel in sulfuric acid solution. Journal of Materials and Environmental Science, 2, 148-155.

[22] Nnanna L.A., Owate I.O., Nwadiuko O.C., Ekekwe N.D. \& Oji W.J. (2013). Adsorption and Corrosion Inhibtion of Gnetum Africana Leaves Extract on Carbon Steel. International Journal of Materials and Chemistry, 3(1), 10-16. 